\title{
Changed control of cervical secretion from infertile ewes previously exposed to oestrogenic clover pasture
}

\author{
N. R. Adams and B. Y. Tang \\ CSIRO Division of Animal Production, Private Bag, Wembley, Western Australia 6014, Australia
}

\begin{abstract}
Summary. The amount of cervical mucus recovered from control ovariectomized ewes increased with increasing doses of oestradiol benzoate (OB), while the maximum Spinnbarkeit of mucus occurred at an intermediate dose of OB. Neither the amount nor the Spinnbarkeit of mucus varied with the dose of $\mathrm{OB}$ in ewes with permanent infertility caused by grazing oestrogenic pasture (clover-affected ewes). Furthermore, the increase in Spinnbarkeit of cervical mucus seen in normal ewes treated over a 3-day period with $O B$ or with implants containing oestradiol did not occur in affected ewes. In control ewes treated repeatedly with $\mathrm{OB}$, production of mucus declined within 5 days, but no change in secretion was detectable in clover-affected ewes. Therefore, neither the amount nor the duration of oestrogenic stimulation affected the cervical mucus in ewes with clover disease. Affected ewes produced more mucus than did controls in the absence of oestrogenic stimulation. It is concluded that the relatively normal volume of mucus in affected ewes treated with OB results largely from autonomous production. The Spinnbarkeit does not increase in these ewes because the ability of the cervix to respond to oestrogen is impaired.
\end{abstract}

\section{Introduction}

If ewes are exposed to oestrogenic clover for several years, they may develop an infertility from which they never recover (Schinckel, 1948). Such ewes have 'clover disease' and exhibit a variety of changes of the kind normally attributed to the organizational effects of oestrogen, including a reduced surge of luteinizing hormone after treatment with oestradiol (Findlay et al., 1973), histological metaplasia of the cervix which then looks like uterus (Adams, 1976a), slight masculinization of the external genitalia (Adams, 1979a) and slight decrease in female behaviour and a slight increase in the degree of male behaviour after treatment with androgen in later life (Adams, 1981a). However, in contrast to the permanent infertility seen in female rodents after treatment with oestrogen during organogenesis, the infertility in ewes with clover disease does not depend primarily on changes in the central nervous system but results from a failure of the cervix to act as a reservoir for spermatozoa (Lightfoot, Croker \& Neil, 1967). Not only is the cervix changed histologically (Adams, 1976a) but the cervical mucus has an abnormally low Spinnbarkeit (Adams, 1976b). The reduced Spinnbarkeit, which probably reflects changes in the cervical secretion which contribute to the poor sperm transport, results from an abnormal response of the cervix to oestrogenic stimulation (Adams, 1979b). The present work examines the effects of oestrogen treatment on the cervical secretion of affected ewes to understand why it is possible to recover a normal volume of secretion without the development of a normal Spinnbarkeit.

\section{Materials and Methods}

Forty (40) 7-year-old Merino ewes were studied. These originated from the same flock, but 20 had grazed an almost pure sward of the highly oestrogenic Yarloop cultivar of subterranean clover for 
3 years and were infertile; only 3 had lambed after their last mating. The 20 control ewes had grazed non-oestrogenic pasture for this period and were of normal fertility ( $17 \mathrm{had}$ lambed). At the end of this time all the ewes were run together on non-oestrogenic pasture for 3 years and were ovariectomized 2 years before the study began.

Cervical mucus was collected and examined as described previously (Adams \& Tang, 1979). Briefly, all the available mucus from around the cervical os was aspirated into a $1 \mathrm{ml}$ pipette. The mucus was expelled on to a clean glass slide, weighed, and the Spinnbarkeit determined with another glass slide. The mucus was then diluted with 5 volumes of $0.15 \mathrm{M}$-sodium thiocyanate in $0.9 \%(\mathrm{w} / \mathrm{v}) \mathrm{NaCl}$, centrifuged, and the supernatant fluid assayed for protein by the method of Lowry, Rosebrough, Farr \& Randall (1951) and for carbohydrate by the method of Hewitt (1937).

Three experiments were carried out, but more than 3 months elapsed between each experiment to avoid any carry-over effect.

Study 1 . To determine the responsiveness of the ewes to different doses of oestradiol benzoate, groups of 15 affected and 15 control ewes were each divided into 3 groups of 5 which were injected i.m. with 20,50 or $120 \mu \mathrm{g}$ oestradiol benzoate (Intervet (Aust.), Sydney) in ml peanut oil daily for 3 days. Cervical mucus was collected $24 \mathrm{~h}$ after each injection. The experiment was repeated 3 times between January and June at intervals of more than 2 months, so that each ewe received each dose of oestradiol benzoate.

Study 2. The effect of repeated stimulation with oestradiol benzoate was examined in 11 affected and 11 control ewes which were injected i.m. daily for 8 days during October with $40 \mu \mathrm{g}$ oestradiol benzoate in $1 \mathrm{ml}$ oil. Samples of mucus were collected before the start of the experiment and $24 \mathrm{~h}$ after each injection.

Study 3. The response to oestrogen implants was examined in 20 affected and 20 control ewes during March to see whether the fluctuation in concentrations of oestrogen in the plasma after injection of oestradiol benzoate affected the nature of the mucus response. Half of each group was injected i.m. with $40 \mu \mathrm{g}$ oestradiol benzoate in $1 \mathrm{ml}$ peanut oil daily for 3 days while the other ewes were implanted subcutaneously with Silastic tubing (i.d. $3.35 \mathrm{~mm}$, o.d. $4.65 \mathrm{~mm}$; Dow Corning Aust., Blacktown, N.S.W., Australia) which contained a $4 \mathrm{~cm}$ length of crystalline oestradiol-17 $\beta$ and was sealed at both ends. Samples of mucus were collected by pipette daily for 3 days and examined as above.

Results were analysed statistically by split-plot analysis of variance. A logarithmic transformation was applied to all the data on mucus weight to make the variances more homogeneous. Values for affected and control ewes were analysed separately in the dose-response experiment (Study 1) because the failure of the affected ewes to respond masked the responses of the normal ewes.

\section{Results}

\section{Study 1: response to dose}

As shown in Table 1, the amount of mucus collected from control ewes increased significantly $(P<0.05)$ with increasing dosing of oestradiol benzoate but the amount collected from infertile ewes did not change. The Spinnbarkeit also varied with the dose of oestradiol benzoate in control ewes $(P<0.05)$, but did not change in affected ewes. The dose of oestradiol benzoate did not affect the concentration of protein or carbohydrate in mucus and differences in the total amounts of protein and carbohydrate recovered did not reach statistical significance.

At all doses, the Spinnbarkeit of mucus increased over the 3-day collection period (Table 2; $P<0.001)$, but the Spinnbarkeit from control ewes increased at a greater rate than that of affected ewes $(P<0.001)$. The weight of mucus collected changed over the 3 -day period $(P<0.05)$, declining on the 3rd day in both groups (Table 2).

No other differences were observed between control and affected ewes. 
Table 1. Effect of dose of oestradiol benzoate on cervical mucus from control and affect ewes

\begin{tabular}{|c|c|c|c|c|}
\hline & \multicolumn{3}{|c|}{ Dose of oestradiol benzoate } & \multirow{2}{*}{$\begin{array}{c}\text { Significance } \\
\text { (ANOV) }\end{array}$} \\
\hline & $20 \mu \mathrm{g}$ & $50 \mu \mathrm{g}$ & $120 \mu \mathrm{g}$ & \\
\hline \multicolumn{5}{|c|}{ Wet weight (mg)* } \\
\hline Control & $68(51-89)$ & $129(103-162)$ & $188(150-235)$ & $P<0.05$ \\
\hline Affected & $150(107-211)$ & $108(75-156)$ & $150(108-209)$ & NS \\
\hline \multicolumn{5}{|c|}{ Spinnbarkeit $(\mathrm{cm}) \dagger$} \\
\hline Control & $6 \cdot 9 \pm 1 \cdot 1$ & $10 \cdot 8 \pm 1 \cdot 3$ & $8 \cdot 7 \pm 1 \cdot 2$ & $P 0.05$ \\
\hline Affected & $7 \cdot 7 \pm 1 \cdot 4$ & $8 \cdot 1 \pm 1 \cdot 5$ & $8 \cdot 9 \pm 1 \cdot 4$ & NS \\
\hline \multicolumn{5}{|c|}{ Weight of carbohydrate $(\mu \mathrm{g}) \dagger$} \\
\hline Control & $203 \pm 49$ & $233 \pm 32$ & $306 \pm 49$ & NS \\
\hline Affected & $383 \pm 100$ & $330 \pm 93$ & $299 \pm 65$ & NS \\
\hline \multicolumn{5}{|c|}{ Weight of protein $(\mathrm{mg}) \dot{\dagger}$} \\
\hline Control & $1 \cdot 75 \pm 0.33$ & $1.92 \pm 0.36$ & $2 \cdot 17 \pm 0 \cdot 39$ & NS \\
\hline Affected & $2.43 \pm 0.56$ & $2 \cdot 70 \pm 0.73$ & $1.83 \pm 0.27$ & NS \\
\hline
\end{tabular}

* Geometric mean with $95 \%$ confidence limits.

$\uparrow$ Mean \pm s.e.m.

Table 2. Overall mean \pm s.e.m. or $95 \%$ confidence limits of Spinnbarkeit and weight of cervical mucus from control and affected ewes during 3 daily treatments with oestradiol benzoate, pooling all doses

\begin{tabular}{lccr}
\hline & Day 1 & Day 2 & \multicolumn{1}{c}{ Day 3 } \\
\hline Spinnbarkeit (cm) & & & \\
$\quad$ Control & $4 \cdot 5 \pm 0.9$ & $9 \cdot 2 \pm 1 \cdot 2$ & $12 \cdot 6 \pm 1 \cdot 4$ \\
Affected & $5 \cdot 4 \pm 0 \cdot 9$ & $8 \cdot 6 \pm 1 \cdot 1$ & $8 \cdot 9 \pm 1 \cdot 4$ \\
Wet weight (mg) & & & \\
$\quad$ Control & $130(106-159)$ & $133(110-162)$ & $94(75-118)$ \\
Affected & $147(117-185)$ & $158(129-192)$ & $104(79-137)$ \\
\hline
\end{tabular}

\section{Study 2: duration of response}

Significantly more mucus was collected from affected ewes than from controls in the absence of oestrogenic stimulation (back transformed means and $95 \%$ confidence limits being 183 $(130-257) \mathrm{mg} v s 17$ (9-32) $\mathrm{mg}, t=3 \cdot 21, P<0.01)$. Repeated daily treatment of the control ewes for 8 days with oestradiol benzoate resulted in an initial increase in the amount of mucus collected, followed by a decline starting on the 2nd day (Fig. 1). After the initial response, the concentration of carbohydrate and, to a lesser extent, protein in the mucus increased with continued treatment (Fig. 1). This reflected an increasing refractoriness. The Spinnbarkeit increased for 3 days and then declined.

In contrast, the increase in amount of mucus in the vagina of affected ewes after injection of oestradiol benzoate was not statistically significant, the Spinnbarkeit did not change and so refractoriness could not be detected (Fig. 1).

\section{Study 3: responses to implants}

The mucus produced in response to implants containing oestradiol-17 $\beta$ was very similar to that 

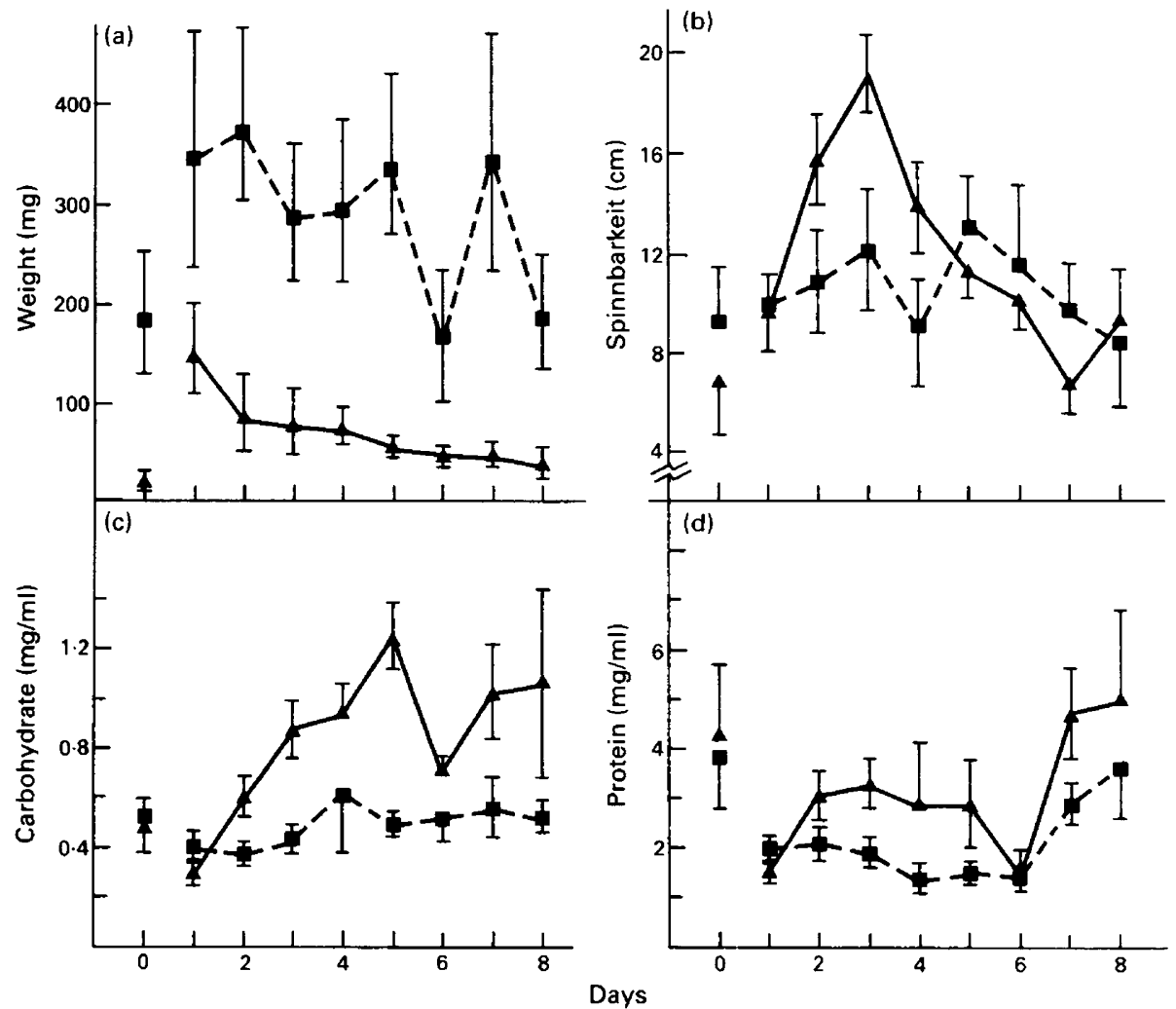

Fig. 1. Mean \pm s.e.m. (or $95 \%$ confidence limits for weight) values for (a) weight, (b) Spinnbarkeit, (c) concentration of carbohydrate, and (d) concentration of protein for control $(\boldsymbol{\Lambda}-\mathbf{A})$ and affected ewes ( $\square-\boldsymbol{\square})$, of cervical mucus before and during 8 daily treatments with $40 \mu \mathrm{g}$ oestradiol benzoate.

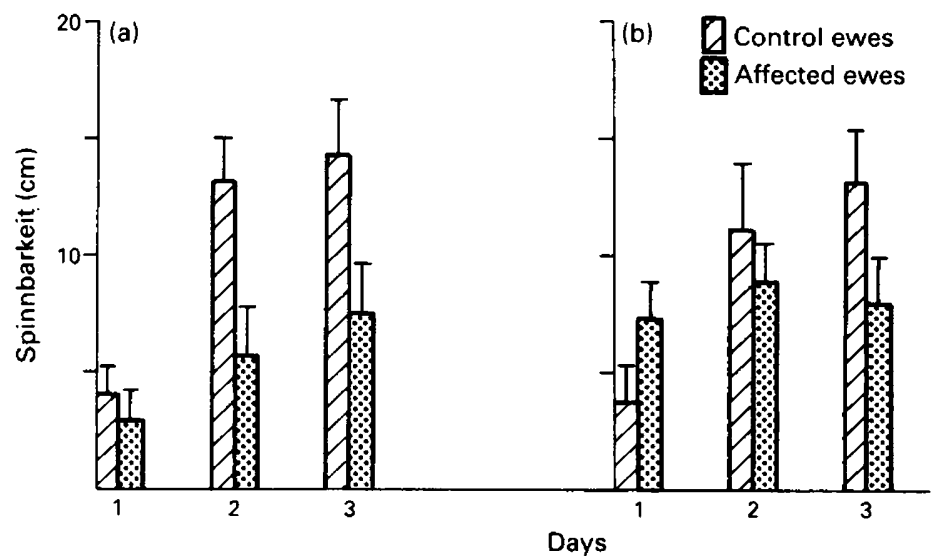

Fig. 2. Mean \pm s.e.m. values for Spinnbarkeit of cervical mucus from control and affected ewes during 3 days treatment with (a) $40 \mu \mathrm{g}$ oestradiol benzoate daily or (b) implants containing oestradiol-17 $\beta$. 
produced after injections of oestradiol benzoate. The Spinnbarkeit increased over the 3-day collection period in the control ewes but not in the affected ewes (Fig. $2 ; P<0.001$ ). In this study, the mean Spinnbarkeit of mucus was lower in the affected ewes than in the controls $(P<0.05)$. There were no other differences between affected and control ewes and no significant differences between implanted and injected ewes, for any of the characteristics of mucus which were studied.

\section{Discussion}

The most obvious feature of these results is that effect of oestrogen on cervical secretion was diminished in the clover-affected ewes. In the control ewes, increasing doses of oestradiol benzoate increased the weight of mucus and affected the Spinnbarkeit in the manner described previously (Adams \& Tang, 1979) but no such changes were seen in affected ewes. A previous attempt to detect such a difference in response to oestrogen between control and affected ewes was unsuccessful (Smith, 1971) but, in that study the group size was smaller, and the ewes were pretreated with progesterone which can directly affect the nature of the secretion (Adams, 1981b). Furthermore, in that study mucus was collected by cotton swabs rather than by aspiration. The weight of material recovered by cotton swabs is much greater, but it is probable that this technique collects vaginal transudates as well as cervical mucus (Wagner \& Levin, 1980), so the results are not directly comparable. The control ewes in the present study also rapidly became refractory to oestradiol benzoate, but secretion did not decline in the affected ewes. The onset of refractoriness in the control ewes was more rapid in Study 2 than in Study 1, or in the work by Smith \& Kelly (1980), but the pattern of results is clear. In summary, the amount of secretion recovered from affected ewes was independent of either the dose or the duration of oestrogenic stimulation. The ewes had been removed from oestrogenic pasture several years before study, so the result is not due to a direct pharmacological effect of the phyto-oestrogen.

A second difference between the groups was the production of substantial amounts of mucus by the cervix of clover-affected ewes in the absence of oestrogenic stimulation (Fig. 1). As shown by the large standard error, such autonomous production varied greatly among ewes, so that the mean amount of mucus recovered from clover-affected ewes varied somewhat from experiment to experiment (Table 1; Fig. 1). Such autonomous production is consistent with previous findings on intact ewes at dioestrus (Tang \& Adams, 1978) and with the rate of protein and glycoprotein synthesis being greater in the cervix of ovariectomized clover-affected ewes than in controls (Tang \& Adams, 1981).

Previously, it has been difficult to understand why the Spinnbarkeit should be depressed while other characteristics of the mucus appeared to be normal (Adams, 1976b). Unlike the other characteristics of mucus, a high Spinnbarkeit develops only after several days' stimulation with oestrogen so it was suggested (Adams, 1979b) that affected ewes were not stimulated by oestrogen for a sufficient length of time. Injection of oestradiol benzoate results in changing plasma concentrations of oestradiol (Cheng \& Johnson, 1974) and it seemed possible that affected ewes may have had a more rapid metabolic clearance of oestradiol or a reduced period of binding by the oestrogen receptor, so that each individual stimulus was of shorter duration. However, neither of these explanations is likely because a similar difference in Spinnbarkeit occurred even when the ewes were given continuous oestrogenic stimulation by means of implants (Fig. 2). It is also obvious from Fig. 1 that the duration of action of oestradiol benzoate was not limited by a more rapid onset of refractoriness in affected ewes. The most likely explanation for the lack of a significant increase in the Spinnbarkeit of the mucus in affected ewes is that all the effects of oestrogen on mucus are diminished, but the autonomous production of mucus results in a reasonable volume of mucus being available for collection, so that the failure of mucus volume to respond to oestrogen is not immediately recognizable.

Both the reduced responsiveness to oestrogen and the autonomous production of cervical 
mucus can be understood as part of the basic change that occurs in ewes with clover disease. As described in the 'Introduction', a number of lines of evidence indicate that prolonged exposure to phyto-oestrogens can produce 'organizational' effects on the ewe akin to those normally produced by steroidal oestrogens during fetal life (Adams, 1981a). The 'organizational' effects of oestrogen on the metabolism of the genital tract have been shown to include increased metabolic activity in unstimulated ovariectomized animals together with impaired responsiveness to oestrogen (Kohrman \& Greenberg, 1968; Tang \& Adams, 1981). For example, Mori (1975) found that ovariectomized adult mice which had been given oestrogen neonatally (during the period of organogenesis) had a higher mitotic rate in the uterine and vaginal epithelia than did controls, but the mitotic rate did not increase in response to oestrogenic stimulation. These changes in mitotic rate are analogous to the changes in secretion of mucus in ewes with clover disease. Furthermore, the cervical mucus collected at natural oestrus from ewes that had been exposed to diethylstilboestrol in utero has a lower Spinnbarkeit than mucus from control ewes (N. R. Adams, unpublished). It appears reasonable to suggest that, as with the other changes in ewes with permanent infertility due to phyto-oestrogens, the changes in cervical mucus in affected ewes may be explained by effects of phyto-oestrogens during adult life similar to the effects of oestrogen which cause differentiation during organogenesis.

We thank M. R. Sanders for assistance.

\section{References}

Adams, N.R. (1976a) Pathological changes in the tissues of infertile ewes with clover disease. J. comp. Path. 86, 29-35.

Adams, N.R. (1976b) Cervical mucus changes in infertile ewes previously exposed to oestrogenic subterranean clover. Res. vet. Sci. 22, 216-221.

Adams, N.R. (1979a) Masculinisation of the external genitalia in ewes with clover disease. Aust. vet. J. 55, 22-24.

Adams, N.R. (1979b) Altered response of cervical and vaginal epithelia to oestradiol benzoate in ewes after prolonged exposure to oestrogenic pasture. $J$. Reprod. Fert. 56, 611-613.

Adams, N.R. (1981a) A changed responsiveness to oestrogen in ewes with clover disease. J. Reprod. Fert., Suppl. 30, 223-330.

Adams, N.R. (1981b) Characteristics of oestrogeninduced refractoriness in ovine cervical secretion. $J$. Endocr. 90, 309-314.

Adams, N.R. \& Tang, B.Y. (1979) Changes in ovine cervical mucus in response to oestrogen treatment. $J$. Reprod. Fert. 57, 261-266.

Cheng, H.C. \& Johnson, D.C. (1974) Temporal changes in serum estradiol and prolactin in immature female rats given a single injection of oestradiol benzoate. Steroids 24, 657-664.

Findlay, J.K., Buckmaster, J.M., Chamley, W.A., Cumming, I.A., Hearnshaw, H. \& Goding, J.R. (1973) Release of luteinizing hormone by oestradiol-17 $\beta$ and a gonadotrophin-releasing hormone in ewes affected with clover disease. Neuroendocrinology 11, 57-66.

Hewitt, L.F. (1937) Separation of serum albumin into two fractions. II. Observations on the nature of the glycoprotein fraction. Biochem. J. 31, 360-366.

Kohrman, A.F. \& Greenberg, R.E. (1968) Permanent effects of estradiol on cellular metabolism of the developing mouse vagina. Devl Biol. 18, 632-650.
Lightfoot, R.J., Croker, K.P. \& Neil, H.G. (1967) Failure of sperm transport in relation to ewe infertility following prolonged grazing on oestrogenic pastures. Aust. J. agric. Res. 18, 755-765.

Lowry, O.H., Rosebrough, N.J., Farr, A.L. \& Randall, R.J. (1951) Protein measurement with the Folin phenol reagent. J. biol. Chem. 193, 265-275.

Mori, T. (1975) Effects of postpubertal oestrogen injections on mitotic activity of vaginal and uterine epithelial cells in mice treated neonatally with oestrogen. J. Endocr. 64, 133-140.

Schinckel, P.G. (1948) Infertility in ewes grazing subterranean clover pastures. Observations on breeding behaviour following transfer to 'sound' country. Aust. vet. J. 24, 289-294.

Smith, J.F. (1971) Studies on ovine infertility in agricultural regions of Western Australia: cervical mucus production by fertile and infertile ewes. Aust. J. agric. Res. 22, 513-519.

Smith, J.F. \& Kelly, R.W. (1980) Cervical mucus and oestrous behaviour responses to oestrogens in sheep: progesterone-oestrogen relationships and role of progesterone pretreatment. Anim. Reprod. Sci. 3, $137-147$.

Tang, B.Y. \& Adams, N.R. (1978) Enzyme activities and protein and carbohydrate concentrations in cervical secretions at dioestrus in normal ewes and ewes with permanent phyto-oestrogenic infertility. Aust. J. biol. Sci. 31, 241-246.

Tang, B.Y. \& Adams, N.R. (1981) Oestrogen receptors and metabolic activity in the genital tract after ovariectomy of ewes with permanent infertility caused by exposure to phyto-oestrogens. $J$. Endocr. 89, 365-370.

Wagner, G. \& Levin, R.J. (1980) Electrolytes in vaginal fluid during the menstrual cycle of coitally active and inactive women. J. Reprod. Fert. 60, 17-27. 